


Centimeter

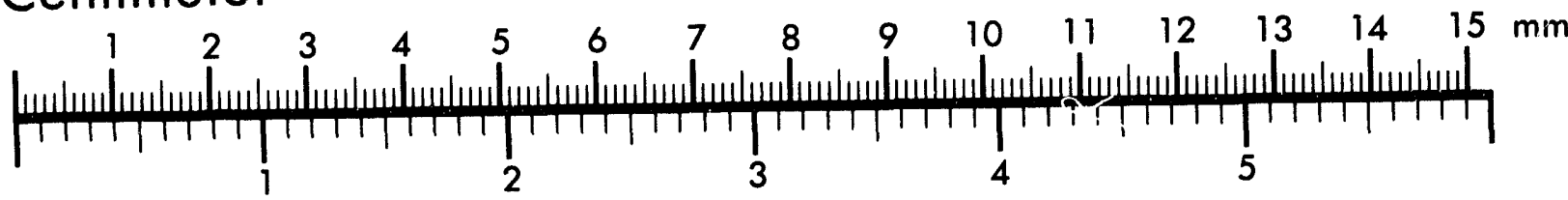
Inches


MANUFACTURED TO AIIM STANDARDS

BY APPLIED IMAGE. INC.

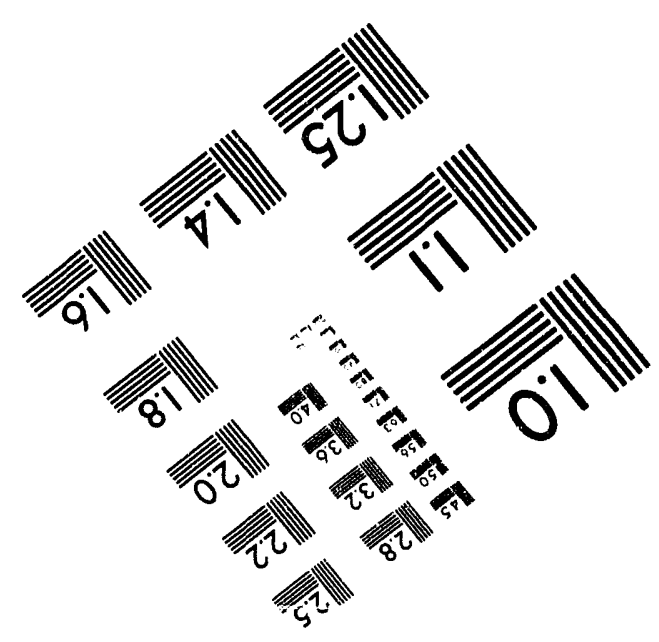



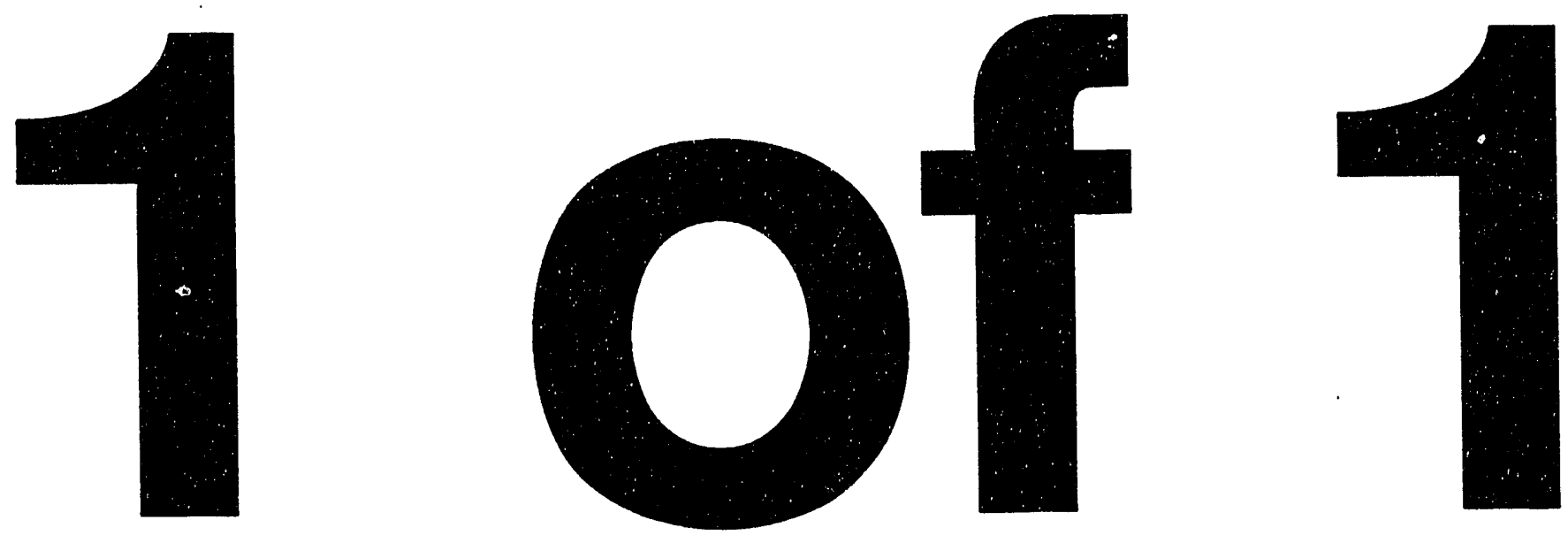
SAND93-0552

Distribution

Unlimited Release

Printed April, 1993

Category UC-700

\title{
EARLY RESULTS ON THE ENVIRONMENTAL INTEGRITY OF W-88 O-RING SEALS
}

\author{
Kenneth T. Gillen \\ Sandia National Laboratories \\ Albuquerque, NM 87185
}

\begin{abstract}
We report experimental measurements for the argon and oxygen permeability coefficients for the new EPDM material (SR793B-80) used for the environmental o-ring seals of the W88. The results allow us to refine our argon gas analysis modeling predictions for W88 surveillance units. By comparing early surveillance results (up to four years in the field) with the modeling, we show that (1) up to this point in time, leakage past the seals is insignificant and (2) the argon approach should be able to inexpensively and easily monitor both integrated lifetime water leakage and the onset of any aging problems. Finally, we provide a number of pieces of evidence indicating that aging of the SR793B-80 material will not be significant during the expected lifetime of the W88.
\end{abstract}




\section{TABLE OF CONTENTS}






\section{INTRODUCTION}

The W88, like most previous weapon systems, uses a number of o-rings as environmental seals. The main purpose of the seals is to protect the internal components from the ingress of potentially damaging external gases such as water vapor and oxygen. Two components contribute to this ingress, permeation of gases through the o-rings and leakage of gases between the o-ring and its metal sealing surface. Since the W88 uses a new EPDM material (SR793B-80) for its environmental o-rings 1,2 , there is considerable interest in monitoring and understanding the performance of these 0 -rings.

In a series of recent reports 3,4 , the second of which concentrated on the W88, we introduced a simple, inexpensive method for estimating the integrated amounts of both water and oxygen that leak into nitrogen-backfilled weapons during their time in the field. Knowledge of the amount of water leakage over the lifetime of a typical unit is important, since excessive leakage will lead to saturation of the desiccant, followed by potential degradation reactions caused by the resulting elevated internal humidity levels. Our approach is based on the use of the argon gas concentration in the weapon as an internal monitor of lifetime water leakage. Since argon is the third most important constituent of air at a concentration of $0.93 \%$, argon leakage into weapons, which are initially backfilled with nitrogen, will parallel water vapor leakage. Unlike water vapor and oxygen which, upon entering a weapon, can react or be absorbed by desiccant, argon is inert. Thus the internal argon concentration allows us to derive reliable estimates of lifetime water and/or oxygen leakage. Since the argon concentration is already monitored as part the normal gas analysis of many field-returned (NMLT, SFT, SLT, etc.) weapons, the information needed to apply the approach is readily and inexpensively available.

Since releasing the earlier report ${ }^{4}$ showing how the argon approach can be applied to the W88, we have obtained accurate experimental values for the argon and oxygen permeability coefficients for the SR793B-80 material. These values now allow us to refine and expand the W8 modeling results presented earlier 4 . In addition, surveillance results for a substantial number of units, which have been in the field for up to approximately four years (real-time aging), are now available to compare to the predictions. This memo will highlight these recent calculations and results.

In addition to tracking the early results for returned units, we would like to have confidence that degradation of the new o-ring material over the intended lifetime of W88 units (up to 40 years) will not lead to enhanced leakage rates later in life. We introduce in this report some gas analysis and o-ring mechanical property results taken on an Accelerated Aging Unit (AAU) which we combine with preliminary accelerated aging results to address this concern. 


\section{EXPERIMENTAL}

The calculations which allow water and oxygen leakage estimates to be made from the measured percentage of argon in a weapon depend upon knowledge of the argon permeability coefficient through the material used to seal the weapon. 3,4 Due to a lack of such data for the newly manufactured SR793B-80 EPDM material, we used literature results for other EPDMs in the calculations for the W88.4 We have now obtained experimental values for argon and oxygen permeability coefficients for the W88 EPDM material. As will be shown below, the oxygen permeability coefficients allow estimates to be made of the oxygen consumption rate inside W88 units.

The SR793B-80 material, which is used for the o-rings that environmentally seal the W88, was obtained as a compression molded sheet of approximate dimensions $15 \mathrm{~cm}$ by $15 \mathrm{~cm}$ by $0.2 \mathrm{~cm}$ thick. The oxygen permeability measurements were conducted on an Oxtran 100A Oxygen Transmission Rate Measurement System. This commercial apparatus is the basis for the ASTM Standard Test Method (D3985-81) for Oxygen Gas Transmission Rate Through Plastic Film and Sheeting Using a Coulometric Sensor. The apparatus uses a horizontal disk of the material of interest (area $\sim 100 \mathrm{~cm}^{2}$ ) to separate an upper chamber from a lower chamber. Oxygen of a known concentration flows through the upper chamber, whereas a nitrogen gas stream flows through the lower chamber and past a coulometric oxygen detector. At equilibrium, a certain amount of oxygen per unit time (dependent on material, material thickness, oxygen concentration above the material and temperature) will flow through the disk and into the detector. This rate can then be used to calculate the permeability coefficient. The instrument, as purchased, had very limited temperature capabilities $\left(\sim 10^{\circ} \mathrm{C}\right.$ gradients across sample at $50^{\circ} \mathrm{C}$ maximum). We have completed extensive modifications to the temperature controlling part of the apparatus so that maximum temperatures of $100^{\circ} \mathrm{C}$ are now possible with less than a $1^{\circ} \mathrm{C}$ gradient across the material. Oxygen permeability coefficient measurements were obtained at $30.5^{\circ} \mathrm{C}, 51.1^{\circ} \mathrm{C}$ and $70.0^{\circ} \mathrm{C}$ with the results shown in Table 1.

Table 1. Permeability Coefficient Results for SR793B-80

Gas

Oxygen

Oxygen

Oxygen

Argon

Argon

\section{Temperature \\ ${ }^{\circ} \mathrm{C}$}

30.5

51.1

70.0

23

23

\author{
$\mathrm{P}$ \\ $\mathrm{ccSTP} / \mathrm{cm} / \mathrm{s} / \mathrm{cmHg}$
}

$1.54 \mathrm{E}-9$

$3.44 \mathrm{E}-9$

$6.07 \mathrm{E}-9$

$9.78 \mathrm{E}-10$

$9.28 \mathrm{E}-10$

Typically, permeability coefficients $P$ have an Arrhenius temperature dependence, which implies that a plot of the $\log$ of $\mathrm{P}$ versus inverse temperature in degrees Kelvin should be linear. Figure 1 shows such a plot for our oxygen permeability 
coefficients; the slope of the line through the results allows us to estimate an Arrhenius activation energy of $7.2 \mathrm{kcal} / \mathrm{mol}$.



Figure 1. Oxygen permeability coefficients versus inverse absolute temperature for the SR793B-80 EPDM material.

Argon permeability coefficient measurements on two separate samples of SR793B-80 were made at $23^{\circ} \mathrm{C}$ by Mocon Modern Controls, Inc. using an apparatus based on a similar concept to the oxygen permeation apparatus. These results are also listed in Table 1. Figure 2 shows Arrhenius plots of argon permeability coefficient data 5 for two other EPDM materials (E529-65 plotted as squares, E692-75 plotted as circles). The linear slopes lead to Arrhenius activation energies of 6.4 and $6.8 \mathrm{kcal} / \mathrm{mol}$, respectively. The average of our two data points for the SR793B-80 EPDM material is also plotted on Fig. 2 and a line with similar slope to the other two EPDMs $(6.6 \mathrm{kcal} / \mathrm{mol}$ activation energy) is drawn through this $23^{\circ} \mathrm{C}$ point in order to get estimates of $\mathrm{P}$ at other temperatures. Our argon permeability coefficient result is $\sim 18 \%$ lower than the result for E692-75 and $\sim 43 \%$ below that of E529-65. Since the last two numbers in the product designation refer to the nominal hardness value for the formulation, these results are 


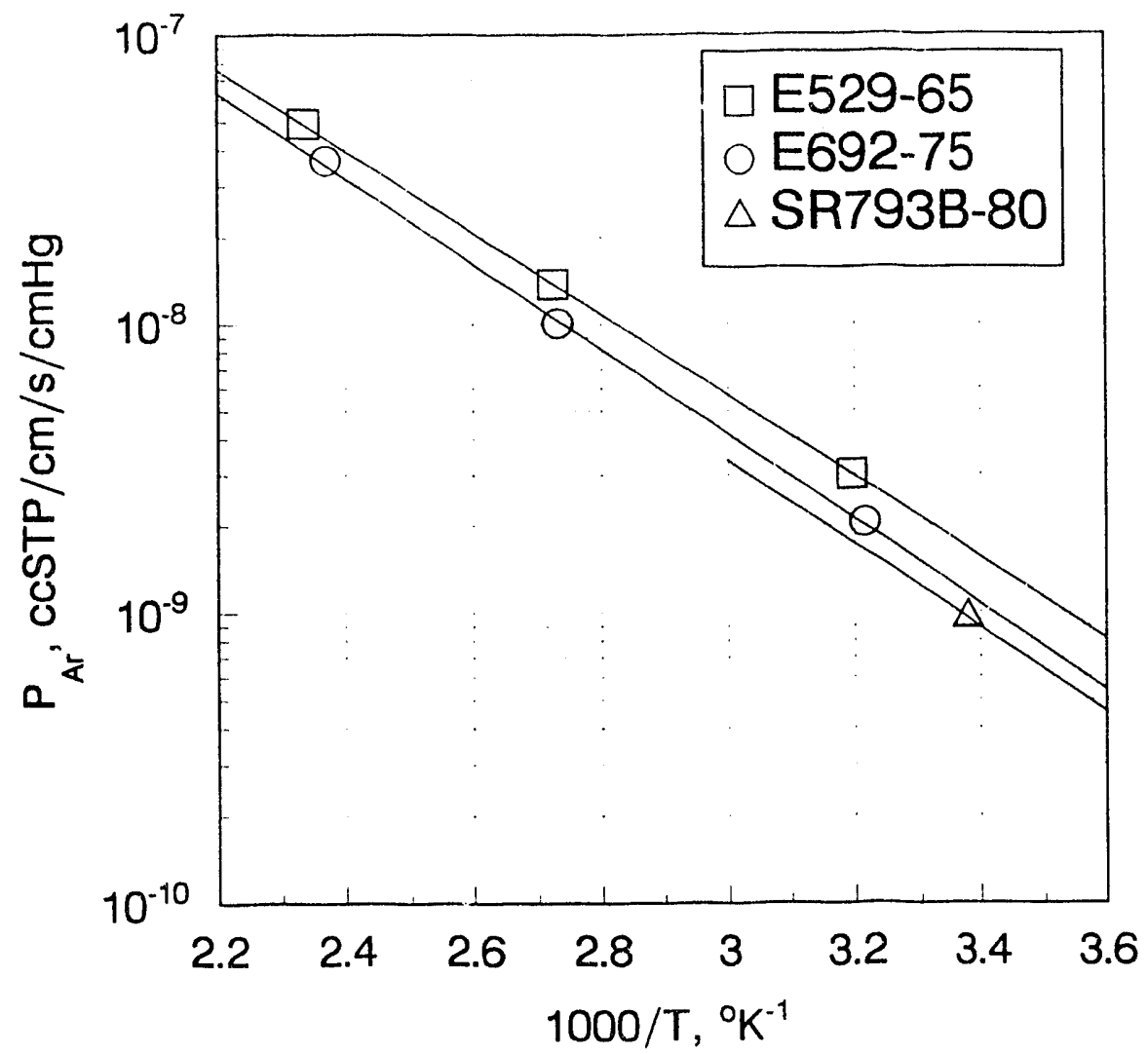

Figure 2. Argon permeability coefficient versus inverse absolute temperature for the three indicated EPDM materials.

consistent with the fact that increases in the hardness (modulus/crosslink density) of a material are often associated with reductions in permeability coefficients.

The mechanical property measurements were done on sets of o-rings removed from two W88 units. The first set came from an SLT unit (S/N 264988) which had experienced $\sim 28$ months of aging in the field. The second set came from a Reentry Body Assembly Accelerated Aging Unit (S/N 386395) which experienced a complex, 12 cycle exposure intended to simulate many years of field exposure. We concentrated our efforts on the three largest W88 environmental o-rings from each set (P/N 38442700,384428 00 and 38442900 ), since these were big enough to allow us to measure uitimate tensile properties. The ultimate tensile tests were done on an Instron Table Model Testing Machine (Model 1000) equipped with pneumatic grips and having an extensometer clamped to the sample. Samples were strained at room temperature using a strain rate of $12.7 \mathrm{~cm} / \mathrm{min}$. Three tests were run on each of the larger o-rings (38442800 and 38442900 ), using approximately $13 \mathrm{~cm}$ long sections cut from the o-ring and an initial jaw separation of $5.1 \mathrm{~cm}$. Since the smaller o-ring (38442700) had only a $10.4 \mathrm{~cm}$ circumference, a smaller initial jaw separation of $-3.7 \mathrm{~cm}$ was used. Tensile property 
results and estimated uncertainties based on the scatter found for repeat determinations are summarized in Table 2.

Table 2. Data Summary

\begin{tabular}{lcccccc} 
Unit & \multicolumn{2}{c}{ Part No. Elongation } & Tensile Strength & $\mathrm{D}^{-1}$ & \multicolumn{2}{c}{ O-Ring Cross-Section, mil } \\
in-plane & $\perp$ to plane
\end{tabular}

Tensile modulus measurements were also obtained on each of the samples listed in Table 2 through the use of our modulus profiling apparatus. 6 Since many measurements can be made on very small pieces of material, modulus profiling is an ideal technique for sample-limited situations. An approximately $5 \mathrm{~mm}$ long section of the o-ring was clamped in a sample holder and polished in cross-section. Multiple measurements (from 3 to 10 per sample) of $\mathrm{D}^{-1}$, the 30 -second inverse tensile compliance (closely related to the tensile modulus), were made at various locations on the cross-section of the o-ring. The results, which showed no dependence on crosssectional position within the estimated experimental scatter of $\sim \pm 10 \%$, are summarized in Table 2.

Before the above mechanical property measurements were conducted, but a long time (months) after the o-rings were removed from the weapon, an attempt was made to measure the cross-sectional o-ring diameters both in the plane direction and perpendicular to the plane. Numerous measurements were made at approximately $10^{\circ}$ intervals for the two bigger o-rings (e.g., $\sim 36$ measurements) and $45^{\circ}$ intervals for the small o-ring. The average values are indicated in Table 2, with the range of values measured reflected in the listed uncertainties.

\section{RESULTS AND DISCUSSION}

\section{Argon Analysis}

In the earlier report on the W88, the theoretical curves relating the argon concentration to the integrated water leakage were derived using literature values for argon permeation $\left(1.4 \times 10^{-9} \mathrm{ccSTP} / \mathrm{cm} / \mathrm{s} / \mathrm{cmHg}\right.$ at $23^{\circ} \mathrm{C}, 1.24 \times 10^{-9} \mathrm{ccSTP} / \mathrm{cm} / \mathrm{s} / \mathrm{cmHg}$ at 
$20^{\circ} \mathrm{C}$ ) through EPDM materials. ${ }^{4}$ We now have argon permeability coefficient measurements at $23^{\circ} \mathrm{C}$ for the exact EPDM used to seal the W88 (Table 1). Since our result at $23^{\circ} \mathrm{C}\left(9.5 \times 10^{10}\right)$ is approximately $30 \%$ lower than the value used for the calculations, we will refine the earlier calculations to reflect our new, more appropriate result. Figure 3, which summarizes the refined calculations, shows predicted argon curves corresponding to water leakage rates of $0,10,30$ and $100 \mathrm{mg} / \mathrm{year}$, assuming average long-term W88 environments of $50 \%$ relative humidity plus $20^{\circ} \mathrm{C}$ (solid curves) and $23^{\circ} \mathrm{C}$ (dashed curves). The changes from the earlier results (Fig. 8 of Ref. 4) are relatively minor with the largest differences (obviously) occurring for the permeationonly curve $(0 \mathrm{mg} /$ year of water leakage).



Figure 3. Predicted percentage argon versus aging time curves for the W88 assuming water leakage rates of $0,10,30$ and $100 \mathrm{mg} /$ year. The solid curves assume average environmental conditions of $20^{\circ} \mathrm{C}$ and $50 \%$ R.H., whereas the dashed curves assume $23^{\circ}$ C plus $50 \%$ R.H.. The water permeation contributions under these two conditions are $111 \mathrm{mg} /$ year and $145 \mathrm{mg} /$ year, respectively. 
Surveillance results are now available for numerous units which have been in the field for up to four years; the argon percentages available from the required gas analyses are plotted as Xs on Fig. 3. Except for one unit which had $0.20 \%$ argon, the remaining units appear to be tracking the permeation-only line, implying water leak rates less than a few $\mathrm{mg} / \mathrm{year}$. In the earlier report, ${ }^{4}$ we showed that the initial helium leak rate results carried out on units just before backfilling with nitrogen were dominated by helium permeation effects and therefore implied an initial water leakage rate of at most a few $\mathrm{mg} /$ year. Thus our conclusions from the early surveillance results indicate that no measurable change in leakage has occurred over the first four years of field aging.

The total water ingress into the weapon is made up of two componentspermeation through the environmental seals and leakage past the seals. Since the permeation contribution is $\sim 130 \mathrm{mg} /$ year, ${ }^{4}$ a few $\mathrm{mg} /$ year of leakage is clearly inconsequential. In the future, as data from units with longer exposures are added to this plot, we will be able to easily and inexpensively determine whether the leakage will remain a minor effect. If, for instance, the results closely tracked the permeation-only curve for the first 10 years and then started moving upwards towards the higher curves, this increase in the leakage with time would indicate aging of the EPDM o-rings.

\section{Oxygen Analysis}

Unlike argon, oxygen which gets into the interior of an initially nitrogenbackfilled weapon can react. Although this is an added complication, analysis of the oxygen content in the weapon can still be useful. ${ }^{4}$ To generate theoretical oxygen curves, we can use the same equations ${ }^{4}$ as those applied to the argon curves, except that parameters (permeability coefficients, partial pressure differences, etc.) appropriate to oxygen are substituted for those appropriate to argon. Since the argon results imply that leakage effects are unimportant, the only sources of oxygen will come from oxygen permeation plus oxygen which is initially dissolved when the weapon is first sealed. We estimated earlier that the amount of argon dissolved initially in internal components was $\sim 0.015 \% 4$; we will therefore assume that $\sim 20$ times as much oxygen $(0.3 \%)$ was initially dissolved before any oxidation reactions. With these assumptions, the modelling leads to the results shown in Fig. 4. The solid and dashed curves again correspond to $20^{\circ} \mathrm{C}$ and $23^{\circ} \mathrm{C}$ average environments, respectively, with the initial slopes of these curves corresponding to initial permeation rates of $\sim 71$ and $81 \mathrm{ccSTP} /$ year for oxygen. The surveillance results are plotted as Xs on Fig. 4. If no oxygen reactions were occurring, the experimental results should approximately follow the theoretical curves. Instead, the oxygen concentrations at early times average about one sixth of the expected result for the internal contribution and the rate of increase of oxygen with time is about one sixth of the rate predicted from oxygen permeation. These results imply that the rate of oxygen consumption is approximately five sixths of the permeation rate, or approximately 60 to $70 \mathrm{ccSTP}$ of oxygen consumed internally per year.

Following the oxygen results in addition to the argon results can be advantageous for several reasons. In addition to estimates of the oxygen consumption rates, 


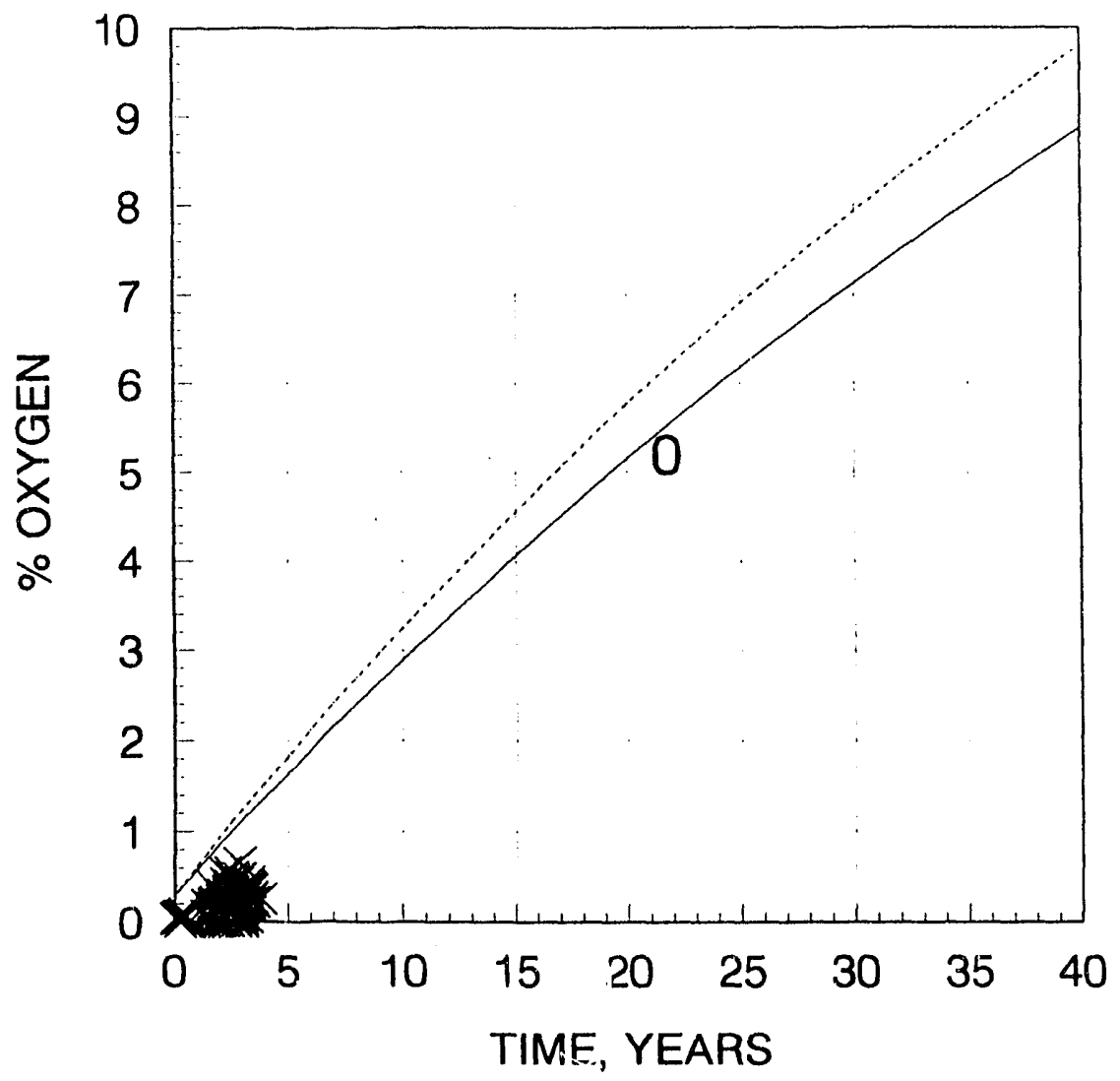

Figure 4. Predicted percentage oxygen versus aging time curves for the W88 assuming no leakage contribution to oxygen ingress. The solid curve assumes average environmental conditions of $20^{\circ} \mathrm{C}$, whereas the dashed curve assumes $23^{\circ} \mathrm{C}$.

comparison of the oxygen and argon data points for a given unit may point to suspicious data. For example, the oxygen content of the unit with $0.2 \%$ argon $(4$ months in the field) was only $0.07 \%$, si nilar to other oxygen results for units which had spent 3-5 months in the field. This indicates the possibility of a bad argon measurement for this unit. Another interesting piece of information which might come from tracking the oxygen results would be the observation of a sudden increase in the oxygen consumption rate for older units. This could indicate that some internal component was starting to degrade quickly.

\section{RBA (Reentry Body Assembly) AAU (Accelerated Aging Unit) Gas Data}

A W88-0/MK5 RBA AAU (a War Reserve unit selected from the Pantex production line in early, 1990) was subjected to a complex 360 day accelerated aging 
exposure from July 17, 1990 to July, 1991. Figure 5 shows the 30 day cyclic exposure which was repeated 12 times. During each cycle, a gas sample was extracted and analyzed; Table 3 shows the results found for argon and oxygen.

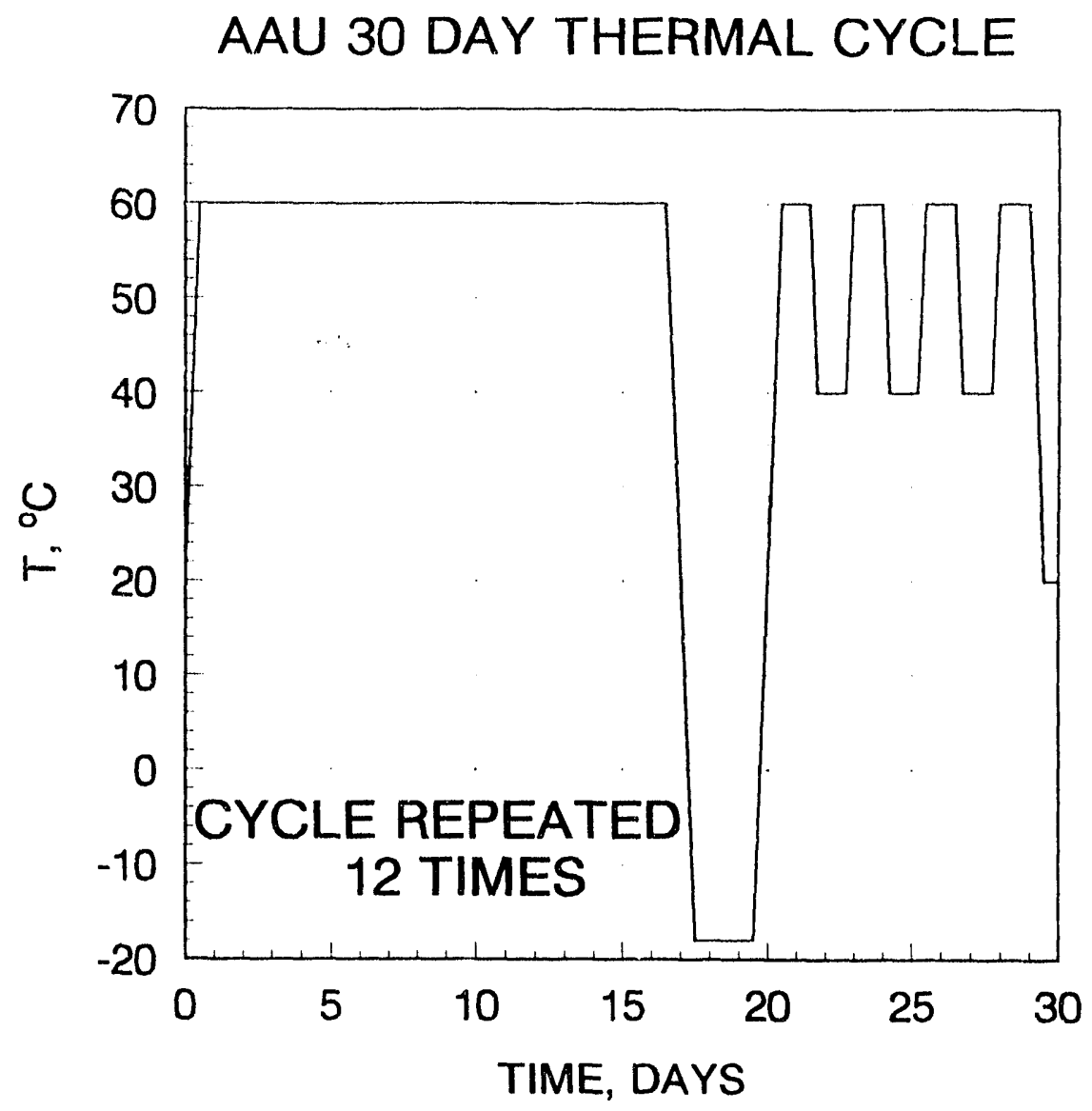

Figure 5. Schematic of 30 day cyclic exposure which was repeated 12 times for the AAU.

The argon results, which are somewhat better behaved than the oxygen results, indicate that the argon concentration at the end of the 360 day exposure is $\sim 0.035 \%$. We can as usual apply our modelling equations ${ }^{4}$ to the AAU results, being careful to note that the permeation of argon occurs at higher temperatures (see Fig. 5). We simplify the complicated cyclic exposure by assuming that during each of the 12 cycles, permeation occurred at $60^{\circ} \mathrm{C}$ for 20 days, at $40^{\circ} \mathrm{C}$ for 3 days and at an average of $50^{\circ} \mathrm{C}$ for 2.5 days (permeation during periods below $40^{\circ} \mathrm{C}$ was insignificant). Using the argon permeability coefficients at $40^{\circ} \mathrm{C}, 50^{\circ} \mathrm{C}$ and $60^{\circ} \mathrm{C}$ obtained from Fig. 2 (the SR793B-80 line) in eq. 
Table 3. AAU Gas Analysis Results

$\begin{array}{lcc}\text { Date } & \text { \% Argon } & \text { \% Oxygen } \\ 7 / 17 / 90 & 0 & 0 \\ 8 / 3 / 90 & 0 & 0 \\ 8 / 31 / 90 & 0.01 \pm 0.06 & 0 \\ 10 / 2 / 90 & 0.02 \pm 0.06 & 0.06 \pm 0.03 \\ 11 / 1 / 90 & 0.08 \pm 0.06 & 1.25 \pm 0.03 \\ 11 / 30 / 90 & 0.03 \pm 0.06 & 0.06 \pm 0.03 \\ 12 / 28 / 90 & 0.02 \pm 0.04 & 0.07 \pm 0.06 \\ 1 / 30 / 91 & 0.03 \pm 0.04 & 0.08 \pm 0.06 \\ 3 / 1 / 91 & 0.04 \pm 0.04 & 0.22 \pm 0.06 \\ 4 / 1 / 91 & 0.04 \pm 0.04 & 0.12 \pm 0.07 \\ 4 / 30 / 91 & 0.03 \pm 0.03 & 0.25 \pm 0.06 \\ 5 / 29 / 91 & 0.03 \pm 0.03 & 0.15 \pm 0.06 \\ 6 / 27 / 91 & 0.04 \pm 0.03 & 0.38 \pm 0.06 \\ 7 / 22 / 91 & 0.03 \pm 0.03 & 0.11 \pm 0.06\end{array}$

(13) of Ref. 4 leads to theoretical predictions for the AAU experiment. Figure 6 plots the line corresponding to the theoretical prediction in the absence of leakage for the time-dependent argon concentration during the 12-cycle AAU exposure. Also plotted on the figure are the experimental values (Table 3). As before for the surveillance results, the theoretical line, corresponding to the absence of important leakage effects, does an excellent job of predicting the experimental results.

Beyond showing that leakage was unimportant during the AAU exposure, these results can be combined with estimates for the activation energy of the degradation process responsible for the loss of mechanical properties to yield preliminary estimates on long-term aging of the EPDM o-rings. We are currently carrying out a long-term aging study on the SR793B-80 material and find that an Arrhenius activation energy of $-26 \mathrm{kcal} / \mathrm{mol}$ is appropriate for its macroscopic mechanical properties (tensile elongation). An earlier, high temperature study on the tensile stress-relaxation modulus behavior of a similar EPDM material by Curro and Salazar 8 found an activation energy of $21.4 \mathrm{kcal} / \mathrm{mol}$. Using this latter, more conservative activation energy together with our simplified summary for the AAU environment $\left(240\right.$ days at $60^{\circ} \mathrm{C}, 30$ days at $50^{\circ} \mathrm{C}$ and 36 days at $40^{\circ} \mathrm{C}$ ) implies that the AAU exposure would be equivalent to $\sim 40$ years at $23^{\circ} \mathrm{C}$ or $\sim 58$ years at $20^{\circ} \mathrm{C}$. Since the anticipated lifetime of W88 units may approach 40 years, the argon AAU results offer preliminary evidence that long-term aging of the EPDM o-rings will not lead to the deveiopment of important leakage effects. 


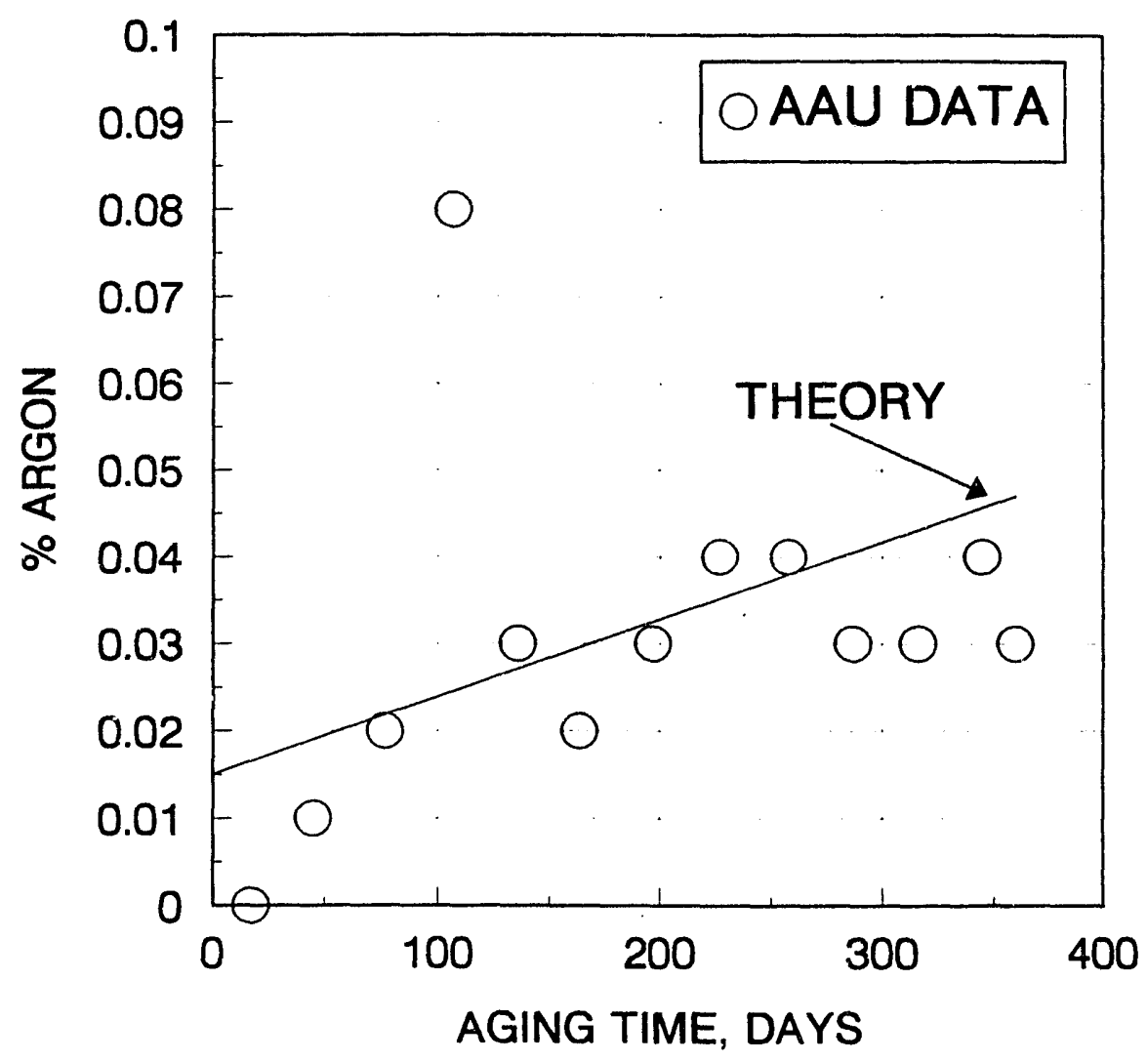

Figure 6. Argon results for the AAU plotted versus time. The line marked theory gives the predicted time-dependent results for the argon concentration in the absence of leakage. This line starts at $0.015 \%$, the estimated contribution of dissolved internal argon.

Using results from Fig. 1, theoretical oxygen AAU data (assuming no leakage) can be generated in a manner similar to the theoretical argon results and compared to the experimental values in Table 3. Figure 7 shows these comparisons. Similar to the situation found for surveillance units, reaction of oxygen reduces the rate of buildup relative to the theoretical permeation line.

One final observation on the AAU gas data concerns the strange looking results for the third cycle in both Figs. 6 and 7. Clearly the fact that both data points are high indicates that the gas analysis was probably correct. However, because argon is inert, the argon concentration can only monotonically increase with time, showing that the data from the third cycle are wrong. The most likely explanation for these elevated values 




Figure 7. Oxygen results for the AAU plotted versus time. The line marked theory gives the predicted time-dependent results for the oxygen concentration in the absence of leakage. This line starts at $0.3 \%$, the estimated contribution of dissolved internal oxygen.

was the existence of a partial air leak into the sample vial sometime between extraction of the sample from the AAU and the gas analysis.

\section{Mechanical Properties of O-rings Obtained from the AAU and from a Surveillance Unit}

Monitoring mechanical properties, including tensile modulus, tensile elongation, tensile strength and compression set is usually helpful for following the degradation of elastomeric seal materials. This is because (1) to a first approximation, a combination of scission (the breaking of covalent bonds) and crosslinking (the formation of covalent bonds between chains) processes dominate aging and (2) mechanical properties of elastomers are especially sensitive to these two processes. Scission effects tend to lower the modulus of an elastomer, whereas crosslinking tends to increase it. If either or both 
processes are important, the ultimate tensile properties will typically degrade. Occasionally, the underlying degradation reactions may lead to an approximate balance between crosslinking and scission, resulting in smaller changes in these three tensile properties. For these cases, significant degradation will be observable through the use of compression set values, since both scission and crosslinking processes tend to increase the magnitude of the set. Therefore, by monitoring changes in these four properties for o-rings from surveillance weapons, we should be able to determine whether important degradation is occurring.

The present study examined these properties for an AAU (S/N 386395) and for an SLT unit (S/N 264988) which had seen 28 months in the field. Using a "conservative" Arrhenius activation energy of $21.4 \mathrm{kcal} / \mathrm{mol}^{8}$, together with the AAU temperature-time profile, we estimated above that the AAU experienced the equivalent of 40 years at $23^{\circ} \mathrm{C}$ or 58 years at $20^{\circ} \mathrm{C}$. Thus the two units under study represent a young unit and a "old" unit.

The first observation to note from the mechanical property measurements of elongation, tensile strength and modulus in Table 2 is the fairly large range of values for each property. This is unfortunate, but characteristic of the SR793B-80 EPDM material. Earlier studies have found that the Shore A hardness of manufactured o-rings and slabs varied from $\sim 74$ to 82 and that modulus measurements on these parts ranged from $\sim 6.5$ to $10.4 \mathrm{MPa}$ (940 to $1500 \mathrm{psi})^{9}$. Similar variations in modulus values are seen for the aged materials in the Table. For each batch of o-rings manufactured, a test slab is made for batch acceptance/quality control purposes. Requirements for the test slab properties include a hardness of $78 \pm 5$, a minimum tensile strength of $8.3 \mathrm{MPa}(1200 \mathrm{psi})$ and a minimum elongation of $100 \%$. If the same specifications applied to o-rings, one of the SLT o-rings (part no. 38442800) would appear to have marginal properties. However, the lot acceptance specifications for slabs are not intended to apply rigorously to finished parts due to necessary processing variations and differences in test methods. The o-ring with reduced tensile properiies has a value of modulus in the upper part of the normal range; this implies a fully cured material with a relatively high crosslink density. As the crosslinking of elastomers increases, the elongation tends to decrease, consistent with the measured value. Based on the available evidence, we conclude that the mechanical property results (magnitude and variation) for the aged o-rings are consistent with expectations for unaged material and therefore offer no evidence of measurable degradation. On the other hand, the relatively large variation in properties found for unaged materials implies that it may be difficult to monitor the early stages of degradation using these properties.

In such instances, compression set measurements can be quite useful. Compression set values are calculated from measurements of o-ring cross sections after the strained o-ring is removed from its o-ring groove. Two components contribute to the set, physical which is reversible and chemical, which is irreversible. Degradation effects are associated with the irreversible chemical contributions to the set. When the o-ring is first removed, the physical contribution is at its maximum and it decays with time, resulting in a time-dependent increase in the o-ring dimension back towards its original value, but limited by any chemical degradation. Compression set measurements are 
often made on surveillance units shortly after removal of the o-rings. In our case, the measurements given in Table 2 were taken many months after removal; these results therefore reflect primarily the desired chemical contribution. Since the nominal o-ring cross-sectional diameters are $70 \mathrm{mil}(\mathrm{P} / \mathrm{N} 38442700)$ and $103 \mathrm{mil}(\mathrm{P} / \mathrm{N} 38442800$ and 38442900 ) and the o-ring groove depths are $52 \mathrm{mil}$ and $70 \mathrm{mil}$, respectively, it is clear from the Table that minimal compression set occurred, implying minimal evidence of degradation.

These results can be added to a continuing body of evidence that strongly suggests no aging problems should occur for this new EPDM material over the W88 lifetime. For instance, compression stress relaxation results of Wilson 10 indicate little chemical degradation for this material after 1.7 year exposures at $70^{\circ} \mathrm{C}$ and $80^{\circ} \mathrm{C}$. In addition, compression set values of only $6.3 \%$ and $7.4 \%$ were found for the EPDM orings after a full scale compatibility test (JT5-18C) on the W88 ${ }^{11}$. Precisely the same material is used to make the o-rings called out for the W89. Comparison of mechanical property data from W89 o-rings analyzed after Core Tests as severe as 2 years at $70^{\circ} \mathrm{C}$ indicated that the Core samples experienced little or no damage ${ }^{12}$.

\section{CONCLUSIONS}

We have obtained experimental measurements for the argon and oxygen permeability coefficients for the new EPDM material (SR793B-80) used for the environmental o-rings of the W88. These results allow us to refine our argon gas analysis modelling predictions for W88 surveillance units. By comparing early surveillance results (up to four years in the field) with the modelling, we conclude that (1) leakage past the seals is insignificant for such exposures and (2) the argon approach should be able to inexpensively and easily estimate the integrated water leakage into units during their lifetimes. The argon method will also be able to easily monitor aging of the o-rings since significant aging effects would eventually lead to enhanced leakage rates for older units.

We have also compared the modelling calculations with gas analysis results from an AAU. Again the results indicate that leakage is unimportant. Since the o-rings in the one year AAU experiment saw the estimated equivalent of approximately 40 to 60 years of ambient aging conditions, the results provide early evidence that aging of the o-rings will not be significant. This conclusion is reinforced by mechanical property measurements on the o-rings removed from the AAU after aging.

\section{ACKNOWLEDGMENTS}

The author would like to acknowledge the helpful assistance of F. P. Freeman and L. Hull in obtaining the gas analysis data and the field-aged and AAU o-rings. 


\section{REFERENCES}

1. M. H. Wilson, "Improved EPDM Elastomer Seal Formulation", Allied-Signal Aerospace Company, Kansas City Division Report BDX-613-3900 (April, 1988).

2. M. H. Wilson, "EPDM Mixing Variability Study", Allied Signal Aerospace Company, Kansas City Division Report KCP-613-4114 (June, 1989).

3. K. T. Gillen, "A Better Method for Estimating Long-Term Ingress of Water into Weapons Based on Argon Gas Concentration", SAND87-0809 (May, 1987).

4. K. T. Gillen, "Argon Gas Analysis to Predict Water Leakage into the W88", SAND90-1852 (August, 1990).

5. Parker O-Ring Handbook, March, 1982.

6. K. T. Gillen, R. L. Clough and C. A. Quintana, "Modulus Profiling of Polymers", Polymer Degradation and Stability, 17, 31 (1987).

7. K. T. Gillen and R. L. Clough, unpublished results.

8. J. G. Curro and E. A. Salazar, J. Appl. Polym. Sci., 19, 2571 (1975).

9. Memo to J. J. Lang, 5153 from K. T. Gillen and P. D. Silva, 1812, dated March 19, 1990.

10. M. H. Wilson, "Accelerated Aging of EPDM and Butyl Elastomers", Allied Signal Acrospace Company, Kansas City Division, Final Report, KCP-613-4129 (August, 1989).

11. Memo to T. D. Hernandez, 5153 from C. Arnold, Jr., 1811, dated November 16, 1990.

12. Memo to C. W. Pretzel, 5354 and R. W. Bradshaw, 8313 from K. T. Gillen and P. D. Silva, 1812 and R. L. Clough, 1811, dated May 11, 1992. 


\section{DISTRIBUTION}

U. S. Department of Energy (2) Albuquerque Operations Office

P. O. Box 5400

Albuquerque, NM 87115

Attn. A. E. Whiteman, WQD

H. T. Season, WPD

U. S. Department of Energy

Amarillo Area Office

P. O. Box 30030

Amarillo, TX 79120

Attn. G. W. Johnson (Actg.)

Los Alamos National Laboratory (5)

Los Alamos, NM 87545

Attn. T. D. Robinson, WX-5, G780

J. M. McAfee, M-7, P950

G. Mortenson, C920

D. Ponton, NWT/NWP

W. Lunsford, WX-1

Lawrence Livermore National Laboratory (2)

P. O. Box 808

Livermore, CA 94550

Attn. J. Lemay, L-322

D. L. Seaton, L-328

Commanding Officer (3)

Program Management Office/SSP

P. O. Box 3504

Sunnyvale, CA 94088-3504

Attn. D. Kletter (SPL 32)

P. Bevelhymer (SPL 32), LMSC 89-70

K. Jew (SPL 32), LMSC 84-40

Allied Signal Aerospace Co. (3)

Kansas City Division

P. O. Box 419159

Kansas City, MO 64141-6159

Attn. Erich Grotheer

Mike Smith

Mark Wilson 
Strategic Systems Programs

1931 Jefferson Davis Hwy, Bldg. CM\#3

Arlington, VA 22202

Attn. K. Tobin, SP2722

Commanding Officer

Naval Weapon Station

Seal Beach, CA 90740-5000

Attn. L. S. Noel, Code 53

Mason and Hanger- Silas Mason Co. (2)

Pantex Plant

P. O. Box 30020

Amarillo, TX 79177

Attn. K. W. Wampler

T. Montgomery

0300 R. L. Schwoebel

0331 S. D. Spray

0335 J. M. Sjulin

0361 J. L. Duncan, Actg.

0361 C. L. Sparks

0362 K. D. Flynn, Actg.

0363 J. N. Middleton

0363 F. P. Freeman

0363 W. Schrader

0363 L. Hull

1800 A. D. Romig

1811 R. L. Clough

1812 C. L. Renschler

1812 K. T. Gillen (10)

1823 J. A. Borders

1824 M. R. Keenan

2472 J. A. Sayre

2472 R. L. Myers

5100 W. C. Nickell

5115 J. O. Harrison

5151 D. D. Tipton

5153 F. F. Dean

5153 E. J. Barkocy

5165 J. A. Anderson

5166 R. C. Hartwig

5167 M. A. Rosenthal

5202 D. J. Bohrer 
5203 C. C. Burks

5354 C. W. Pretzel

7141 Technical Library (5)

7151 Technical Publications

8523-2 Central Technical Files

8711 J. E. Costa

8713 R. W. Bradshaw

7613-2 Document Processing for DOE/OSTI (10) 

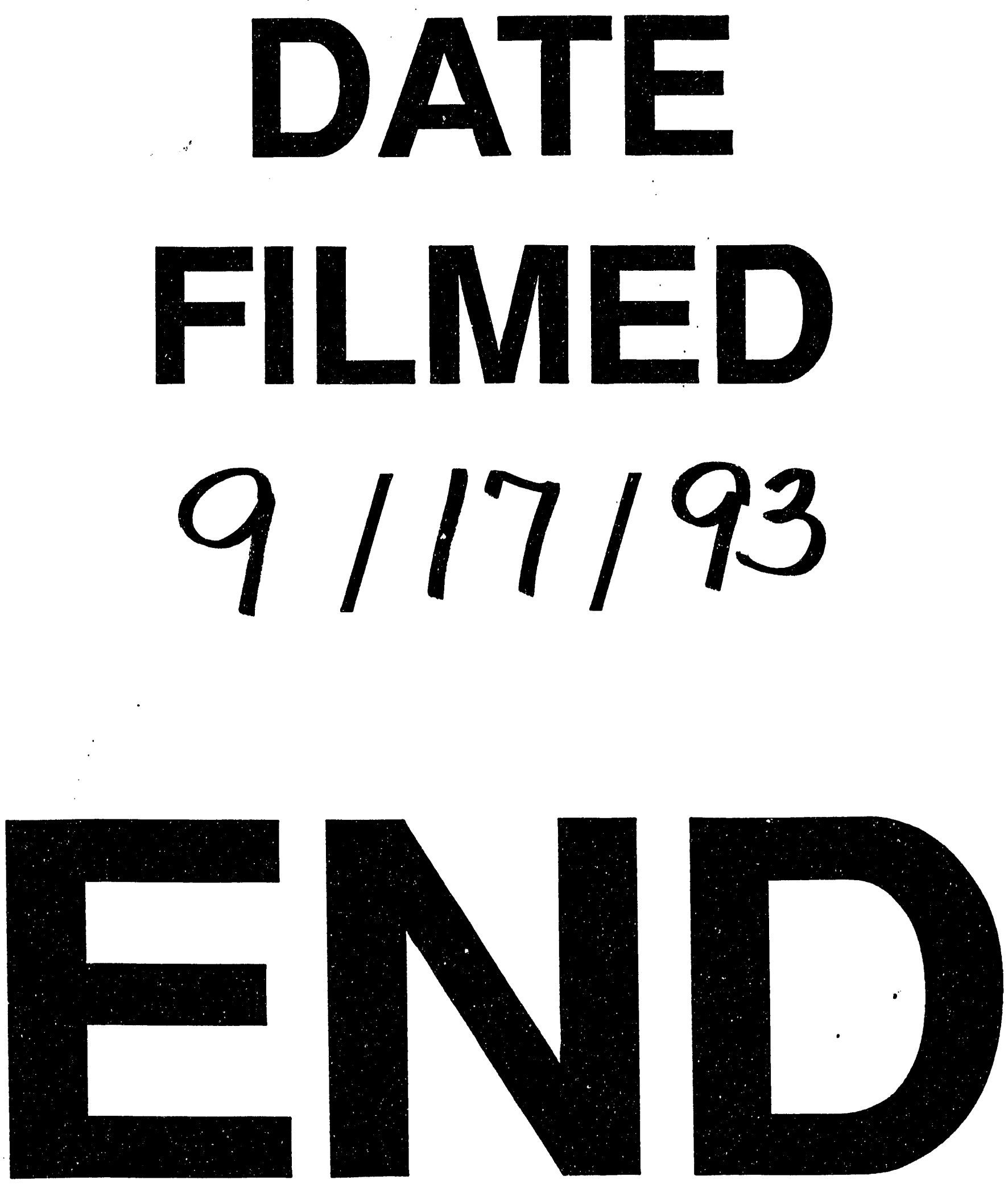
